\title{
Exaggerated BMP4 signalling alters human airway basal progenitor cell differentiation to cigarette smoking-related phenotypes
}

\author{
Wu-Lin Zuo, Jing Yang, Yael Strulovici-Barel, Jacqueline Salit, \\ Mahboubeh Rostami, Jason G. Mezey, Sarah L. O’Beirne, \\ Robert J. Kaner and Ronald G. Crystal \\ Affiliation: Dept of Genetic Medicine, Weill Cornell Medical College, New York, NY, USA.
}

Correspondence: Ronald G. Crystal, Dept of Genetic Medicine, Weill Cornell Medical College, 1300 York Avenue, Box 164, New York, NY 10065, USA. E-mail: geneticmedicineamed.cornell.edu

@ERSpublications

COPD pathogenesis is mediated by BMP4 reprogrammed stem/progenitor cells in human airway http://ow.ly/iWAI30nuWor

Cite this article as: Zuo W-L, Yang J, Strulovici-Barel Y, et al. Exaggerated BMP4 signalling alters human airway basal progenitor cell differentiation to cigarette smoking-related phenotypes. Eur Respir J 2019; 53: 1702553 [https://doi.org/10.1183/13993003.02553-2017].

ABSTRACT Airway remodelling in chronic obstructive pulmonary disease (COPD) originates, in part, from smoking-induced changes in airway basal stem/progenitor cells (BCs). Based on the knowledge that bone morphogenetic protein 4 (BMP4) influences epithelial progenitor function in the developing and adult mouse lung, we hypothesised that BMP4 signalling may regulate the biology of adult human airway BCs relevant to COPD.

BMP4 signalling components in human airway epithelium were analysed at the mRNA and protein levels, and the differentiation of $\mathrm{BC}$ s was assessed using the $\mathrm{BC}$ expansion and air-liquid interface models in the absence/presence of BMP4, BMP receptor inhibitor and/or small interfering RNAs against BMP receptors and downstream signalling.

The data demonstrate that in cigarette smokers, BMP4 is upregulated in ciliated and intermediate undifferentiated cells, and expression of the BMP4 receptor BMPR1A is enriched in BCs. BMP4 induced BCs to acquire a smoking-related abnormal phenotype in vitro mediated by BMPR1A/Smad signalling, characterised by decreased capacity to differentiate into normal mucociliary epithelium, while generating squamous metaplasia.

Exaggerated BMP4 signalling promotes cigarette smoking-relevant airway epithelial remodelling by inducing abnormal phenotypes in human airway BCs. Targeting of BMP4 signalling in airway BCs may represent a novel target to prevent/treat COPD-associated airway disease. 


\section{Introduction}

The human airway epithelium is a pseudo-stratified columnar epithelium, composed of basal stem/ progenitor cells (BCs), intermediate undifferentiated cells, ciliated cells and secretory cells [1-3]. BCs, small cuboidal cells residing on the airway basement membrane, serve as the stem/progenitor cells of human airway epithelium, capable of differentiating into the ciliated and secretory cells that are central to the physical barrier, host defence and mucociliary clearance $[1,2]$. The intermediate cells are BC-derived precursors committed to differentiate into ciliated and secretory cells $[4,5]$.

Cigarette smoking, the major cause of chronic obstructive pulmonary disease (COPD), is associated with marked changes to the morphology of airway epithelium, including BC and intermediate cell hyperplasia, mucous cell hyperplasia, squamous cell metaplasia, loss of ciliated cells, and shortened cilia [5-13]. Increasing evidence supports the concept that reprogramming of airway $\mathrm{BCs}$ is central to the early pathogenesis of cigarette smoking-induced derangement of airway epithelium [14, 15]. BCs isolated from smokers have a significant transcriptomic difference compared with BCs from nonsmokers, including reprogramming of genes associated with the genetic risk for COPD [16]. Smoking skews the normal function of BCs by suppression of airway epithelial differentiation and tight junction formation [12, 17], in part through the cross-talk between BCs and other cell types [5, 18]. For example, activation of epidermal growth factor (EGF) receptor (EGFR) in BCs alters the differentiation programme of BCs towards the squamous and epithelial-mesenchymal transition (EMT)-like phenotypes characteristic of smoking-induced changes to airway epithelium in vivo [5].

In the assessment of human airway epithelium in healthy nonsmokers, asymptomatic smokers and COPD smokers, we observed that bone morphogenetic protein 4 (BMP4) expression is upregulated in airway epithelium of asymptomatic smokers and COPD smokers. Based on the knowledge that BMP4, a secreted transforming growth factor (TGF)- $\beta$ family member, controls epithelial progenitor function in the developing and adult mouse lung by regulating early mesoderm formation [19], airway branching morphogenesis [20] and promoting proximal airway differentiation [21], and induces EMT-like changes in a human airway epithelial cell line [22], we hypothesised that excessive BMP4 signalling may play a functional role in dysregulating the biology of adult human airway BCs relevant to smoking and COPD. The data demonstrate that in cigarette smokers, BMP4 expression is upregulated in ciliated and intermediate undifferentiated cells, and BMP4 receptor BMPR1A expression is enriched in BCs. BMP4-treated normal BCs acquire a COPD-like "fatigue" phenotype, characterised by decreased capacity to differentiate into normal mucociliary epithelium, while generating squamous metaplasia. These effects are mediated by BMPR1A/Smad signalling and inhibition of BMPR1A restores the stem/progenitor cell potential of airway BCs, providing a possible target for therapeutic intervention in smoking-induced lung disorders.

\section{Methods}

Human airway epithelium and BCs were obtained from nonsmokers, asymptomatic smokers and COPD smokers by bronchoscopy and in vitro primary BC culture. In vitro primary BC and air-liquid interface (ALI) cultures were carried out to study the effects of BMP4 on BC differentiation. Gene expression of airway epithelium and BCs in vivo and in vitro was assessed by RNA sequencing/microarray and TaqMan real-time (quantitative) PCR (Applied Biosystems, Foster City, CA, USA). Airway epithelial morphology and localisation of proteins were accessed by immunohistochemistry/immunofluorescence staining. Phosphorylation of BMP4 downstream signalling was assessed by Western blot.

Full details are provided in the supplementary material.

\section{Results}

\section{BMP4 is upregulated in airway epithelium of asymptomatic and COPD smokers}

To determine whether cigarette smoking was associated with abnormal BMP signalling in airway epithelium, gene expression of BMPs and BMP antagonists in the large airway epithelium and BCs from nonsmokers, asymptomatic smokers and COPD smokers was quantified by RNA sequencing. Expression of BMP5, BMP6 and BMP antagonists NOG, CHRD and CHRDL2 was very low in both airway epithelium and airway BCs (average fragments per kilobase of transcript per million mapped reads $<0.2$ ). BMP2 and BMP antagonists FST, FSTL3 and TWSG1 were highly expressed in airway BCs compared with expression in complete airway epithelium, and expression did not change in asymptomatic smokers and COPD smokers (supplementary figure S1a and b, and supplementary table SI). BMP7 was expressed in nonsmokers, and mildly increased in asymptomatic smokers and COPD smokers (supplementary figure S1a and supplementary table SI). BMP4 expression was relatively low in nonsmokers, but was significantly upregulated in asymptomatic smokers and COPD smokers in airway epithelium. There was no significant difference between asymptomatic smokers and COPD smokers (figure 1a, supplementary figure S2a and 

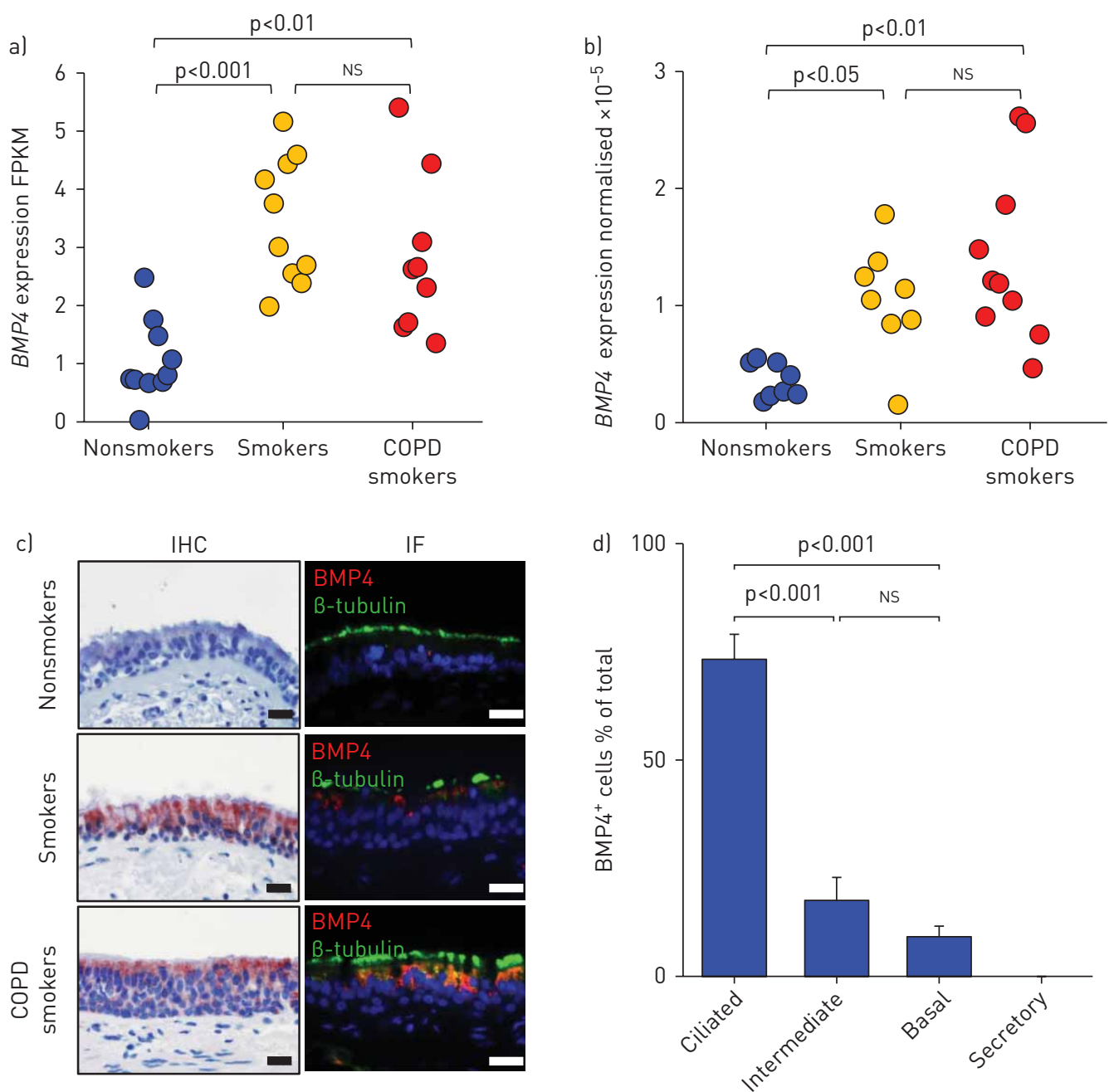

FIGURE 1 Upregulation of bone morphogenetic protein 4 (BMP4) in human airway epithelium of asymptomatic smokers and chronic obstructive pulmonary disease (COPD) smokers. FPKM: fragments per kilobase of transcript per million mapped reads; IHC: immunohistochemistry; IF: immunofluorescence. a) RNA sequencing assessment of BMP4 expression in human airway epithelium of nonsmokers ( $n=10)$, asymptomatic smokers $(n=10)$ and COPD smokers $(n=9)$. b) TaqMan quantitative PCR normalised BMP4 gene expression in human airway epithelium of nonsmokers $(n=8)$, asymptomatic smokers $(n=8)$ and COPD smokers $(n=10)$. c) BMP4 protein expression in human airway epithelium: IHC staining and IF colocalisation of BMP4 (red) and ciliated cell marker $\beta$-tubulin (green) in human airway epithelium of nonsmokers, asymptomatic smokers and COPD smokers. Scale bar: $20 \mu \mathrm{m}$. Nuclei are stained with 4',6-diamidino-2-phenylindole (blue). d) Distribution (percentage of total airway epithelial cells) of $\mathrm{BMP}^{+}$cells in ciliated, intermediate, basal and secretory cells based on IHC staining on asymptomatic smokers $(n=6)$ and COPD smokers $(n=6)$ (based on assessment of a total of 444 cells from 12 different samples). No secretory cells expressed BMP4. NS: nonsignificant.

supplementary table SI). BMP4 upregulation in airway epithelium of asymptomatic smokers and COPD smokers was further confirmed by TaqMan quantitative PCR (figure 1b). Although there was no significant difference in BMP4 expression of airway BCs from nonsmokers, asymptomatic smokers and COPD smokers, a subgroup of asymptomatic smokers and COPD smokers had higher BMP4 expression than any of the nonsmokers (supplementary figure S2a). Comparing airway epithelium and airway BCs from asymptomatic smokers, BMP4 was highly expressed in the total airway epithelium (supplementary figure S2a), suggesting that upregulated BMP4 is mainly expressed in differentiated airway epithelial cells. The data are in agreement with the in vitro TaqMan data that BMP4 expression increased during BC differentiation in the ALI model (supplementary figure S2b).

Using a unique microarray dataset from human small airway epithelium at multiple time-points (months 0, 3, 6 and 12), we observed that BMP4 was upregulated at all time-points in COPD smokers when compared with nonsmokers (supplementary figure S3). When COPD smokers quit smoking after the initial bronchoscopy at month 0 , their BMP4 expression in small airway epithelium dramatically decreased 
at month 3, and approached the normal level in nonsmokers at months 6 and 12. However, when COPD smokers stopped quitting smoking and re-started smoking after month 3, their BMP4 expression in small airway epithelium increased again (supplementary figure S3). In summary, in addition to large airway epithelium RNA sequencing data, the microarray data confirm that BMP4 expression in human small airway epithelium is also upregulated in COPD smokers and cigarette smoking is a "trigger" for BMP4 expression in airway epithelium.

To determine the expression and localisation of BMP4 protein in human airway epithelium, immunohistochemistry and immunofluorescence staining were carried out on human airway epithelial biopsies. BMP4 protein was barely detected in normal airway epithelium of nonsmokers, but was markedly increased in $\beta$-tubulin ${ }^{+}$ciliated cells of normal airway epithelium from asymptomatic smokers and COPD smokers (figure 1c and supplementary figure S4). In abnormal airway epithelium with BC hyperplasia, mucous cell hyperplasia and squamous metaplasia from asymptomatic smokers and COPD smokers, BMP4 protein was upregulated in ciliated cells as well (figure $3 \mathrm{a}$ and supplementary figure S4). In addition to expression in ciliated cells, BMP4 was also upregulated in a subset of BCs and intermediate cells from asymptomatic smokers and COPD smokers, but was not expressed in secretory cells (figure 1d and supplementary figure S4), which was consistent with the RNA sequencing data in airway BCs. The cellular distribution of $\mathrm{BMP}^{+}$cells from asymptomatic smokers and COPD smokers, which included both normal and abnormal morphologies of airway epithelium, showed that BMP4 was predominately induced in ciliated cells, as well a few intermediate cells and BCs (figure 1d). However, BMP4 protein was not detected in the mesenchyme underneath the epithelial cells (figures $1 \mathrm{c}$ and $3 \mathrm{a}$, and supplementary figure S4).

\section{BMP4 suppresses normal BC proliferation and differentiation}

$\mathrm{BCs}$ are the stem/progenitor cells in human airways, and are able to self-renew and differentiate into normal ciliated and secretory cells. To determine the effect of BMP4 on BC self-renewal and proliferation, we applied BMP4 to cultured normal nonsmoker BCs and identified that BMP4 significantly decreased BC number and suppressed BC proliferation (supplementary figure S5).

To study the effects of upregulated BMP4 on normal BC differentiation, we used ALI culture to assess human airway BC differentiation. The data demonstrated that BMP4 had a broad inhibitory effect on normal BC differentiation into a mucociliary epithelium. Compared with control, airway epithelium generated from BMP4-treated BCs had significantly lower expression of ciliated cell-related genes, including dynein DNAI1, transcription factor FOXJ1, and the transcription factors MCIDAS and RFX2 that control early ciliogenesis (figure $2 \mathrm{a}$ and supplementary figure S6a). Consistent with the gene expression data, immunofluorescence staining of DNAI1 protein showed that BMP4 decreased the proportion of DNAI1 ${ }^{+}$ ciliated cells that were derived from BCs in ALI culture (figure $2 b$, and supplementary figure S6b and c). Moreover, BMP4 significantly suppressed the cilia beating of ciliated cells derived from healthy nonsmoker BCs (supplementary video S1a and d).

Similarly, BMP4 had an inhibitory effect on secretory cell differentiation. The secretory cell-related genes SCGB1A1, SPDEF, MUC5B and TFF3 were significantly downregulated by BMP4 stimulation (figure 2a and supplementary figure S6a). Stimulation of BCs with different levels of BMP4 at various time-points in ALI culture showed that the suppression effects of ciliated and secretory cell differentiation by BMP4 were sustained during differentiation in ALI culture in a concentration-dependent manner (supplementary figure S6a). SCGB1A1 protein was also suppressed by BMP4 stimulation (figure 2b). TaqMan analysis also showed that expression of early differentiation markers for ciliated cells (MCIDAS, DNAH5 and IFT172) and secretory cells (SPDEF and TFF3) was suppressed (supplementary figure S6d) in cultured BCs by BMP4 stimulation. These data suggest that BMP4 begins to modulate the ciliated and secretory cell differentiation programme in BCs at a very early stage.

\section{BMP4 promotes squamous cell differentiation}

As described earlier, BMP4 upregulation in asymptomatic smokers and COPD smokers was associated with abnormal morphology of airway epithelium, including squamous metaplasia (figure 3a and supplementary figure S4). To further confirm this observation, immunofluorescence co-staining of BMP4 with intermediate/squamous cell marker KRT6 was assessed in airway epithelium from nonsmokers, asymptomatic smokers and COPD smokers. In the nonsmoker samples with normal morphology, BMP4 and KRT6 expression levels were very low. However, in the samples from asymptomatic smokers and COPD smokers with normal and squamous metaplasia morphology, expression levels of both BMP4 and KRT6 were markedly increased, and a small subset of BMP4 ${ }^{+}$cells expressed KRT6 (figure 3a). Based on the staining data that BMP4 upregulation appeared to be related to squamous metaplasia, we hypothesised that BMP4 shifted the normal BC differentiation to abnormal squamous cells. To assess this hypothesis, we stimulated human airway BCs with BMP4 in both ALI differentiation culture and BC culture models. 
a)

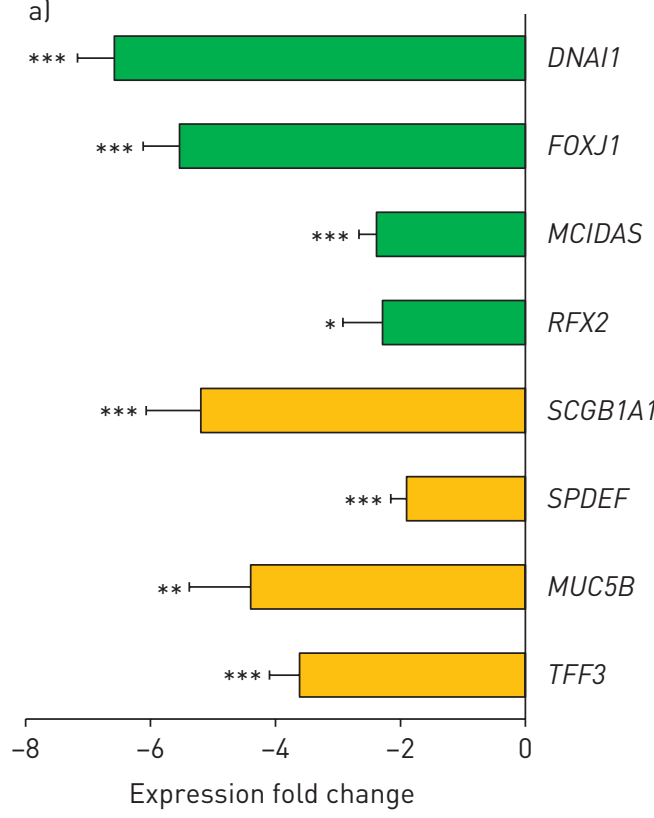

b)
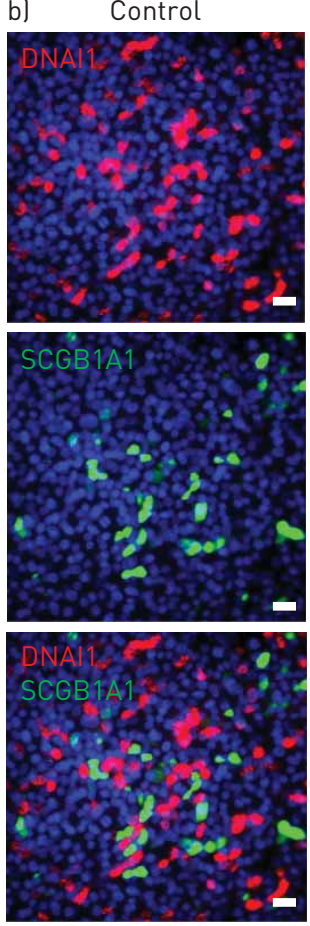

BMP4 $10 \mathrm{ng} \cdot \mathrm{mL}^{-1}$
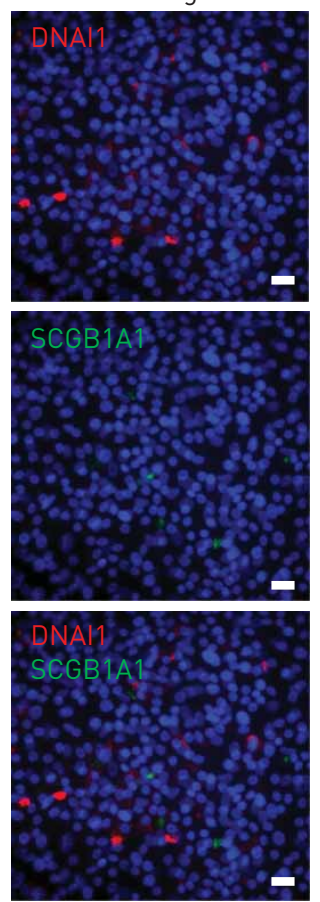

FIGURE 2 Bone morphogenetic protein 4 (BMP4) suppression of normal airway basal stem/progenitor cell (BC) differentiation. ALI: air-liquid interface. To mimic the effects of upregulated BMP4 observed in airway epithelium in asymptomatic smokers and chronic obstructive pulmonary disease smokers, BMP4 (10 $\mathrm{ng} \cdot \mathrm{mL}^{-1}$ ) was added to the basolateral side when the ALI cultures were established, and expression levels of airway epithelial differentiation-related genes and protein were assessed. a) TaqMan assessment of fold change ( $\log _{2}$, BMP4 versus control) in mRNA expression of ciliated cell differentiation-related genes (FOXJ1, DNAI1, MCIDAS and RFX2; green bars) and secretory cell differentiation-related genes (SCGB1A1, SPDEF, MUC5B and TFF3; yellow bars) on airway epithelium after 14 days in ALI culture with BMP4 treatment versus untreated control. $n=3$ or $4 .{ }^{*}: p<0.05 ;{ }^{* *}: p<0.01{ }^{* * *}: p<0.001$. b) Immunofluorescence top staining of ciliated cell marker DNAI1 (red) and secretory cell marker SCGB1A1 (green) on airway epithelium after 28 days in ALI culture with BMP4 $\left(10 \mathrm{ng} \cdot \mathrm{mL}^{-1}\right)$ stimulation from the basolateral side versus untreated control. Nuclei are stained with 4',6-diamidino-2-phenylindole (blue). Scale bar: $20 \mu \mathrm{m}$.

The TaqMan data showed that BMP4 could induce upregulation of a series of squamous cell markers, including IVL, KRT14, KRT6A and KRT6B, in both models (figure 3b, and supplementary figure S7a and e). BMP4 induced upregulation of SFN in ALI culture, but not in BC culture (figure $3 \mathrm{~b}$ and supplementary figure S7e). The TaqMan data were strengthened by the immunofluorescence staining of squamous cell markers on airway epithelium derived from BCs with or without BMP4 stimulation. In airway epithelium derived from BMP4-treated BCs, more cells were positive for squamous cell markers KRT14 and IVL, while in the control groups, the percentages of $\mathrm{IVL}^{+}$and $\mathrm{KRT}_{1} 4^{+}$cells were significantly lower (figure $3 \mathrm{c}$ and supplementary figure S7b-d). BMP4 not only suppressed ciliated and secretory cell differentiation, but also induced squamous cell differentiation in a concentration-dependent manner (supplementary figure S7a).

\section{Effects of BMP4 on fully differentiated airway epithelium}

In addition, stimulation of fully differentiated airway epithelium with BMP4 from the basolateral side also suppressed expression of ciliated cell (FOXJ1 and MCIDAS) and secretory cell (SCGB1A1, SPDEF, MUC5B and TFF3) markers, and induced the upregulation of squamous cell markers (IVL, KRT14 and KRT6A) (supplementary figure S8). However, apical application of BMP4 had no effects on the expression of ciliated cell (FOXJ1), secretory cell (SCGB1A1, MUC5B and TFF3) and squamous cell (IVL and KRT14) markers, and mildly suppressed the expression of ciliated cell marker DNAI1 (supplementary figure S9).

BMP type I receptor enriched in airway BCs mediates BMP4-induced epithelial remodelling

BMP4 signals through two receptor families: BMP receptors (BMPR1A, BMPR1B and BMPR2) and activin receptors (ACVR1, ACVR2A and ACVR2B) [23]. Using the RNA sequencing data, we examined expression of BMP4 receptors in total human airway epithelium and BC samples. The data demonstrated that BMPR1A expression slightly decreased and BMPR1B expression increased in airway epithelium from 

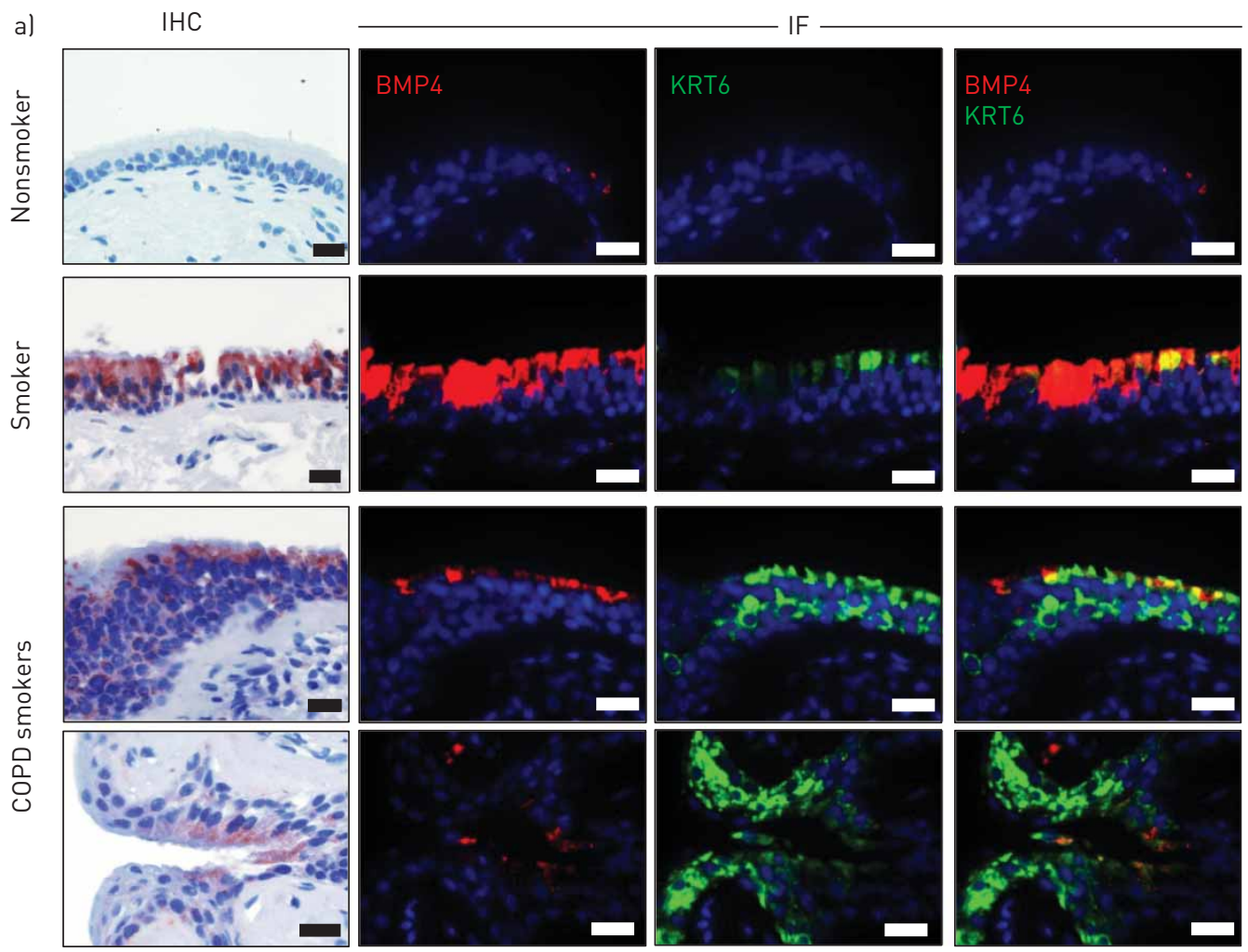

。
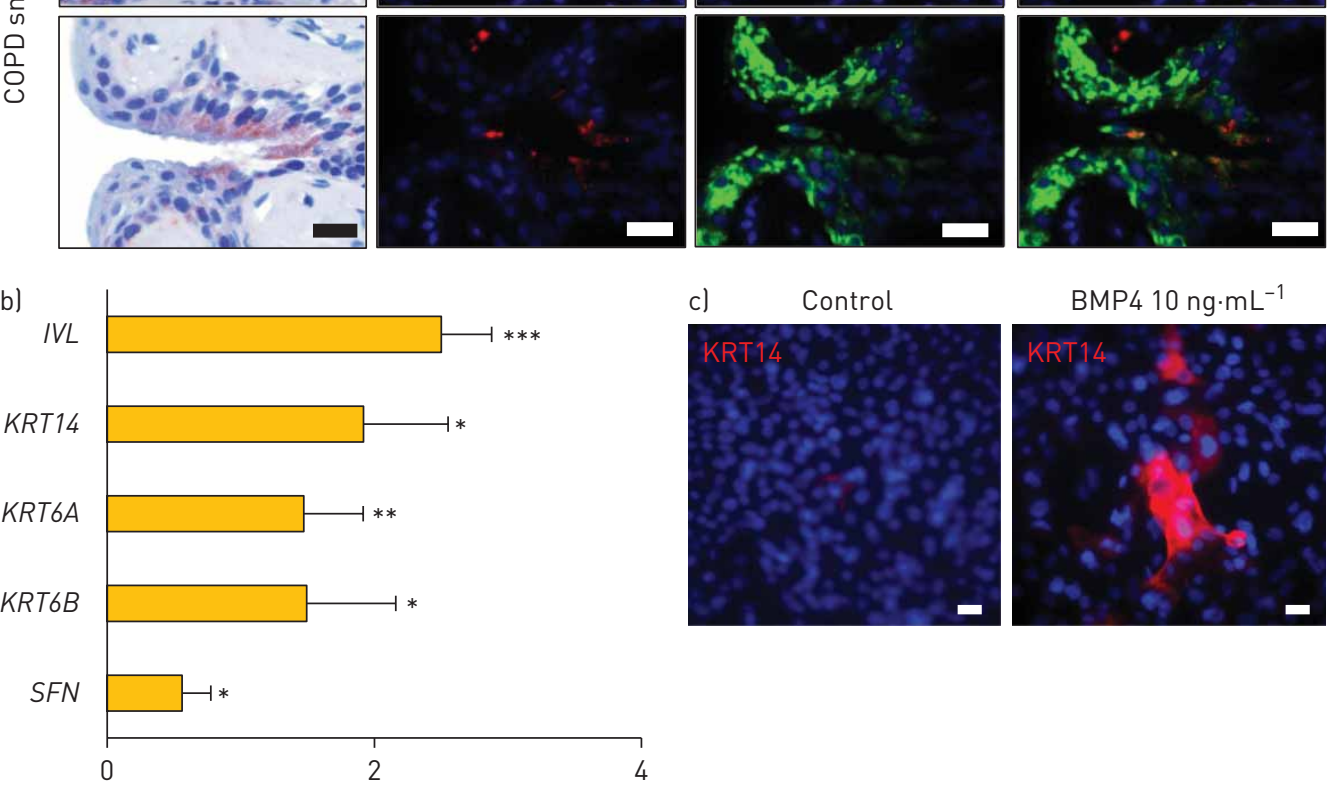

c) Control

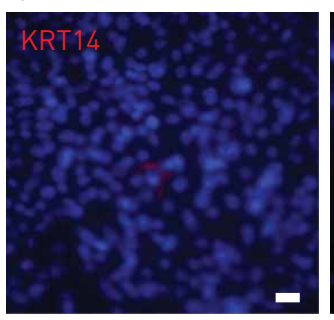

BMP4 $10 \mathrm{ng} \cdot \mathrm{mL}^{-1}$

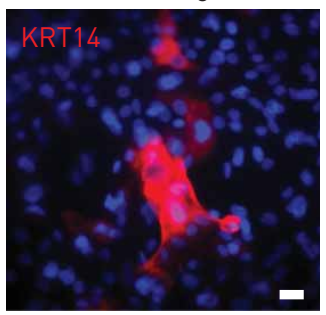

Expression fold change

FIGURE 3 Bone morphogenetic protein 4 (BMP4) induction of differentiation towards squamous cells. IHC: immunohistochemistry; IF: immunofluorescence; COPD: chronic obstructive pulmonary disease; ALI: air-liquid interface. a) From left to right: representative BMP4 IHC staining (positive cells are shown in red), IF staining of BMP4 (red), IF staining of squamous cell marker KRT6 (green), and overlap of BMP4 (red) and KRT6 (green) IF staining. These stains were performed on human airway epithelium of a nonsmoker with normal morphology, an asymptomatic smoker and COPD smokers with abnormal morphology. Nuclei are stained with 4',6-diamidino-2-phenylindole (blue). Scale bar: $20 \mu \mathrm{m}$. The biopsy images with IHC and IF staining in each row were from the same sample. b) TaqMan assessment of fold change ( $\log _{2}$, normalised to control) in the expression of squamous cell-related genes (IVL, KRT14, KRT6A, KRT6B and SFN) from airway epithelium after 14 days in ALI culture with BMP4 $\left(10 \mathrm{ng} \cdot \mathrm{mL}^{-1}\right)$ stimulation from the basolateral side versus untreated control. $\mathrm{n}=3$ or $4^{*}: \mathrm{p}<0.05$; $^{* *}: \mathrm{p}<0.01$; $^{* *}: \mathrm{p}<0.001$. c) IF top staining of the squamous cell marker KRT14 (red) on airway epithelium after 14 days in ALI culture with BMP4 $\left(10 \mathrm{ng} \cdot \mathrm{mL}^{-1}\right)$ stimulation from the basolateral side versus untreated control. Nuclei are stained with 4',6-diamidino-2-phenylindole (blue). Scale bar: $20 \mu \mathrm{m}$.

asymptomatic smokers and COPD smokers, but not in airway BCs. Expression levels of $B M P R 1 B$, $A C V R 2 A$ and $A C V R 2 B$ were higher in airway epithelium compared with expression in BCs (supplementary figure S1c and supplementary table SII). In contrast, BMPR1A, BMPR2 and ACVR1 expression levels were higher in BCs than in complete airway epithelium, suggesting that BMP4 may regulate $\mathrm{BC}$ function through these receptors enriched in BCs. The same pattern of BMP4 receptor enrichment in BCs was observed in nonsmokers, asymptomatic smokers and COPD smokers (figure 4a, 

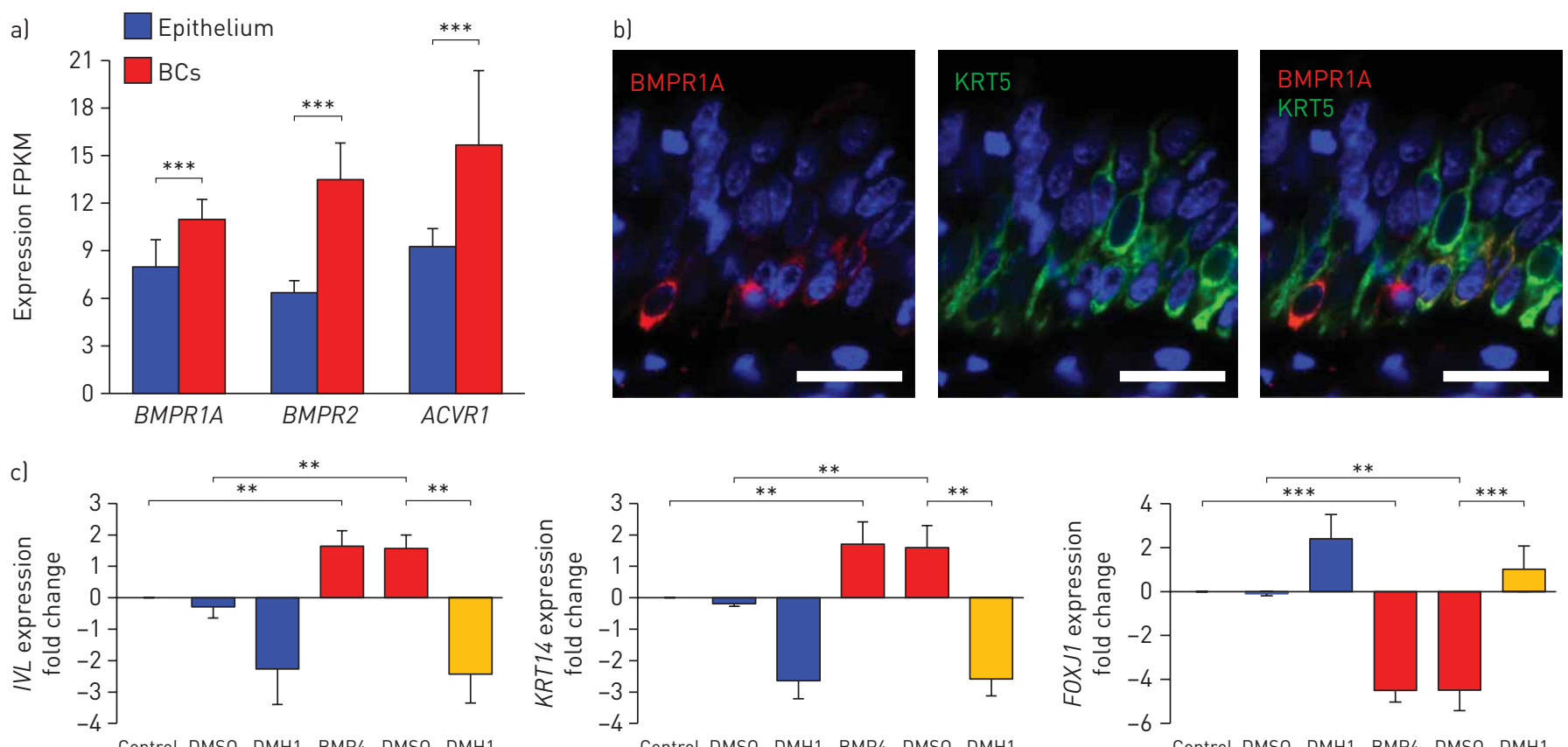

Control DMSO DMH1 BMP4 DMSO DMH1
$+\mathrm{BMP} 4+\mathrm{BMP} 4$

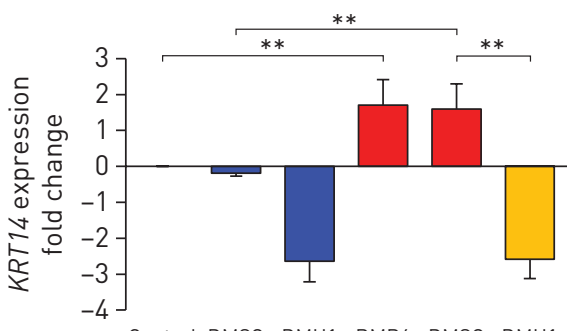

Control DMSO DMH1 BMP4 DMSO DMH1 +BMP4 +BMP4

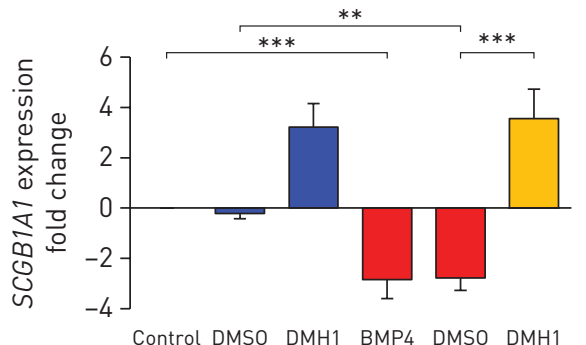
+BMP4 +BMP4

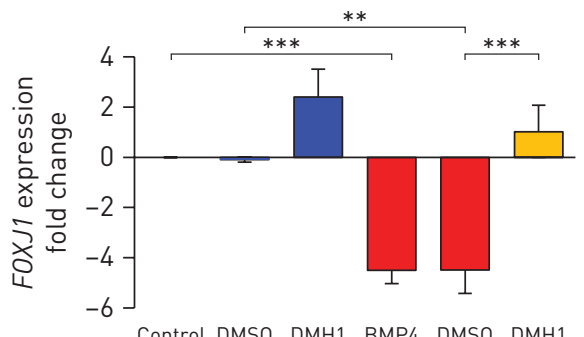

Control DMSO DMH1 BMP4 DMSO DMH1 +BMP4 +BMP4

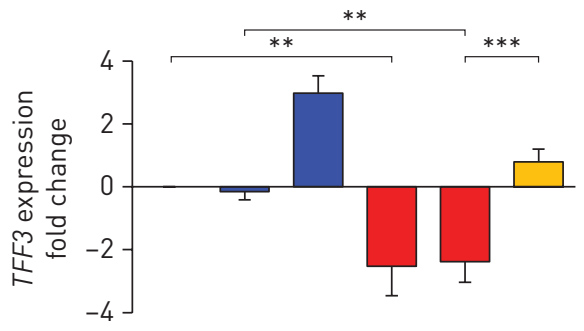

Control DMSO DMH1 BMP4 DMSO DMH1 +BMP4 +BMP4

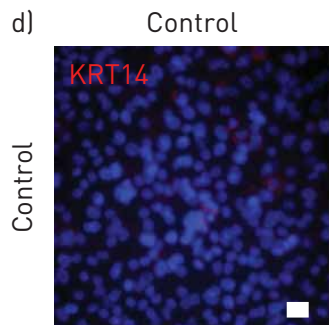
BMP4 $10 \mathrm{ng} \cdot \mathrm{mL}^{-1}$
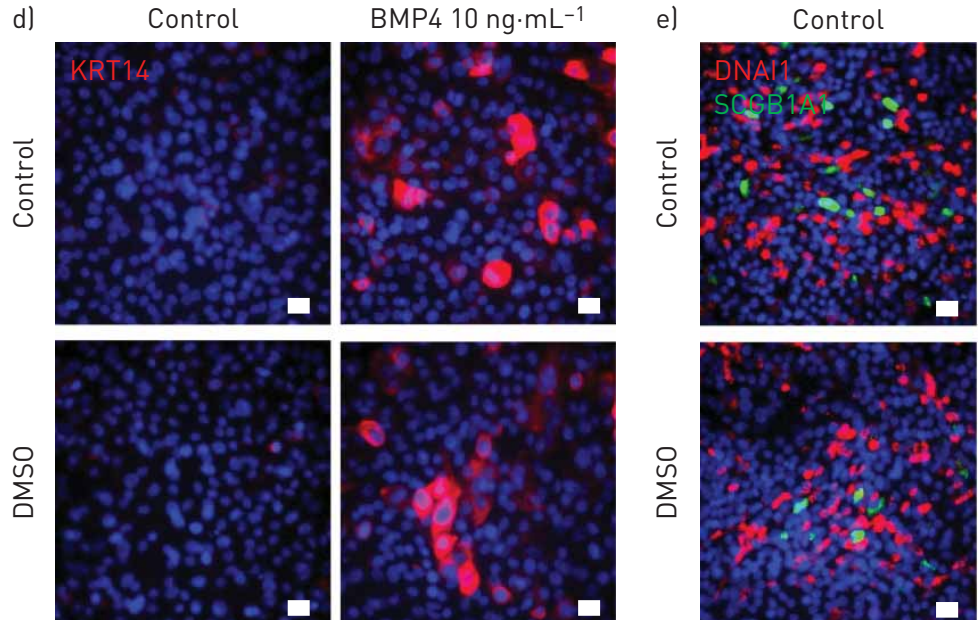

BMP4 $10 \mathrm{ng} \cdot \mathrm{mL}^{-1}$
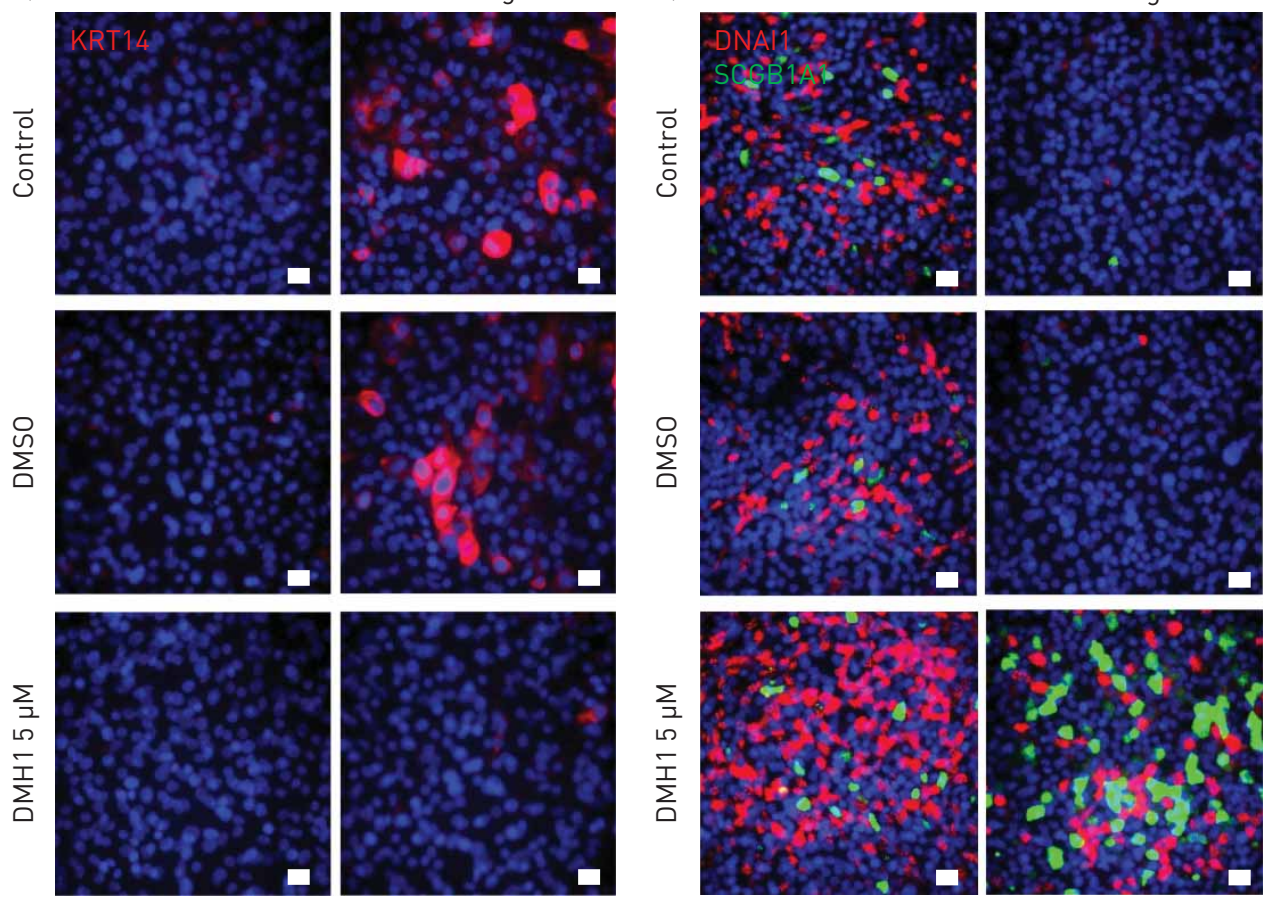

FIGURE 4 Continued.

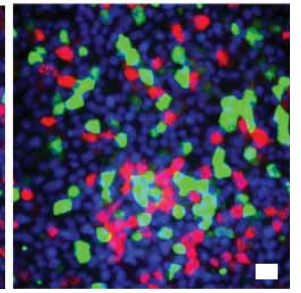




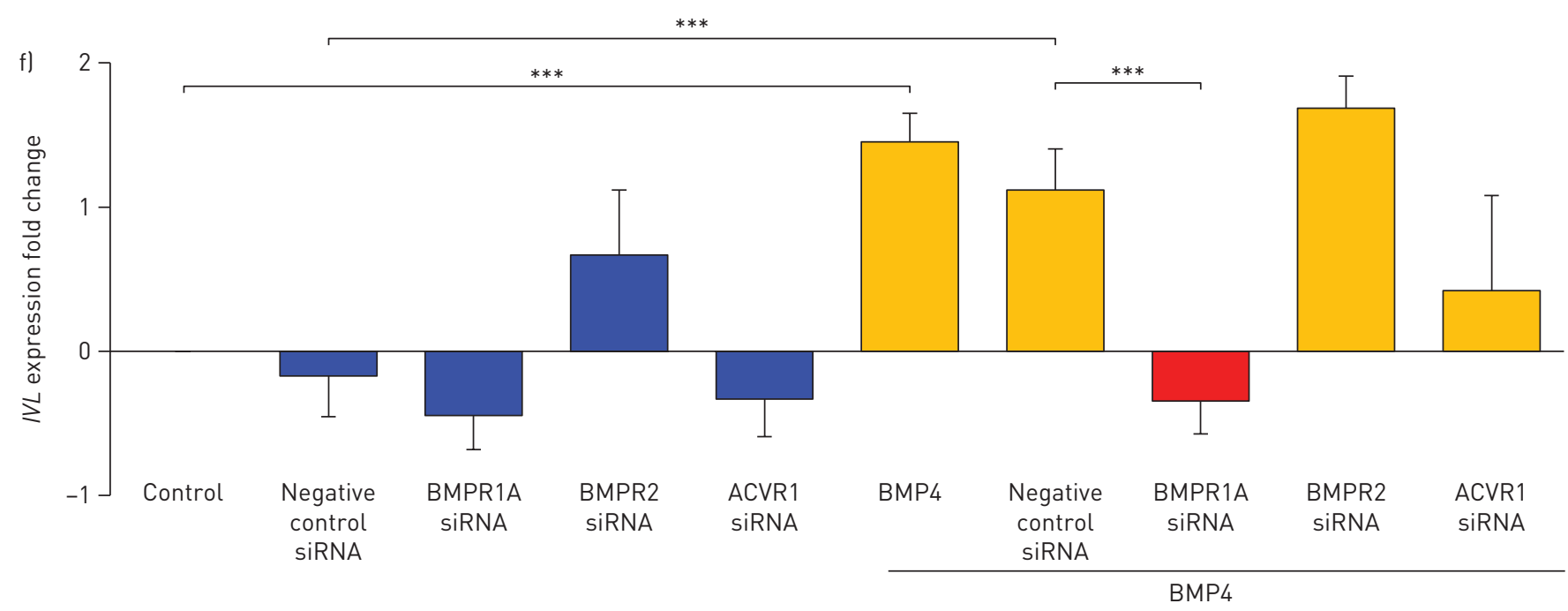

FIGURE 4 Bone morphogenetic protein (BMP) receptor-mediated BMP4-induced airway epithelial remodelling. FPKM: fragments per kilobase of transcript per million mapped reads; BC: basal stem/progenitor cell; DMSO: dimethylsulfoxide; ALI: air-liquid interface. a) RNA sequencing assessment of BMP4 receptors (BMPR1A, BMPR2 and ACVR1) in human airway epithelium ( $\mathrm{n}=29)$ and airway BCs ( $\mathrm{n}=42$ ). Detailed expression data of BMP4 receptors for individuals with different phenotypes are shown in supplementary figure S1c and supplementary table SII. b) Representative immunofluorescence co-localisation of BMPR1A (red) and BC marker KRT5 (green) in normal human airway epithelium. Scale bar: $20 \mu \mathrm{m}$. Nuclei are stained with 4',6-diamidino-2-phenylindole (blue). c) TaqMan analysis of fold change (log 2 , normalised to control) in the expression of various genes related to airway BC differentiation (IVL and KRT14: squamous cells; FOXJ1 and DNAI1: ciliated cells; SCGB1A1 and TFF3: secretory cells). Data were generated from airway epithelium in ALI culture (day 14) with BMP4 (10 $\mathrm{ng} \cdot \mathrm{mL}^{-1}$ ) stimulation from the basolateral side versus untreated control in the absence or presence of BMP type I receptor inhibitor DMH1 (5 $\mu$ M). DMSO was used as the negative control. $n=3$. d) Representative immunofluorescence top staining of squamous cell marker KRT14 (red) on airway epithelium after 14 days in ALI culture. e) Representative immunofluorescence top staining of ciliated cell marker DNAI1 (red) and secretory cell marker SCGB1A1 (green) on airway epithelium after 28 days in ALI culture. Nuclei are stained with 4',6-diamidino-2-phenylindole (blue). Scale bar: $20 \mu \mathrm{m}$. f) TaqMan assessment of expression of the squamous cell marker IVL in BCs with BMP4 (10 $\left.\mathrm{ng} \cdot \mathrm{mL}^{-1}\right)$ stimulation versus untreated control for $48 \mathrm{~h}$

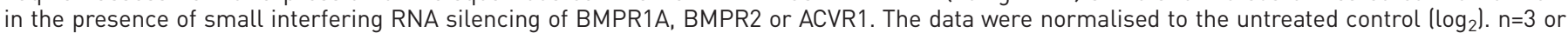
4. ${ }^{* *}: p<0.01 ;{ }^{* * *}: p<0.001$.

supplementary figure S1c and supplementary table SII). Immunofluorescence staining further confirmed that BMPR1A protein was mainly expressed in a subset of $\mathrm{KRT}^{+} \mathrm{BCs}$ (figure $4 \mathrm{~b}$ ).

To assess whether BMP receptors mediate BMP4-induced airway epithelial remodelling, DMH1, a selective inhibitor of BMP type I receptors, was applied to the ALI culture while stimulating BCs with BMP4. The data showed that DMH1 reversed BMP4-induced upregulation of squamous cell markers (IVL and KRT14), and downregulation of ciliated (FOXJ1 and DNAI1) and secretory cell (SCGB1A1 and TFF3) markers (figure 4c). Immunofluorescence staining of airway epithelium with squamous cell marker KRT14, ciliated cell marker DNAI1 and secretory cell marker SCGB1A1 validated that DMH1 could block BMP4-induced airway epithelial remodelling (figure $4 \mathrm{~d}$ and e). Furthermore, DMH1 also reversed BMP4-suppressed cilia cell beating (supplementary video S1).

To further evaluate the specific receptor that mediates BMP4-induced abnormal BC differentiation, BMPR1A, BMPR2 and ACVR1 small interfering RNAs (siRNAs) were applied to cultured BCs with BMP4 treatment versus control. BMPR2 siRNA had no effect on cultured BCs, but BMPR1A siRNA significantly decreased BMP4-induced upregulation of squamous cell marker IVL (figure 4f). Although not significant, ACVR1 siRNA tended to suppress BMP4-induced upregulation of IVL. Additional evidence in ALI differentiation culture confirmed that silencing of BMPR1A could reverse BMP4-induced squamous metaplasia (supplementary figure S10a) and suppression of ciliated cell differentiation (supplementary figure S10b). Efficiency of all the siRNAs was validated by TaqMan analysis of receptor expression in cultured BCs and airway epithelium in ALI culture (supplementary figure S11).

\section{Smad signalling mediates BMP4-induced squamous metaplasia}

To assess whether BMP4 downstream Smad signalling was activated by BMP4 on human airway BCs, Western blot analysis of phosphorylated (p)-Smad1/5/8 was performed on BCs in ALI culture. BMP4 activated Smad1/5/8 phosphorylation at $1 \mathrm{~h}$, and the activation continued but with weaker signalling at 5 and $24 \mathrm{~h}$ (figure 5a). To evaluate whether Smad signalling mediates BMP4-induced squamous metaplasia, Smad4, which translocates p-Smad1/5/8 to the nucleus, was silenced by siRNA in cultured BCs (supplementary figure S12). TaqMan analysis showed that BMP4-induced expression of squamous cell 
a)

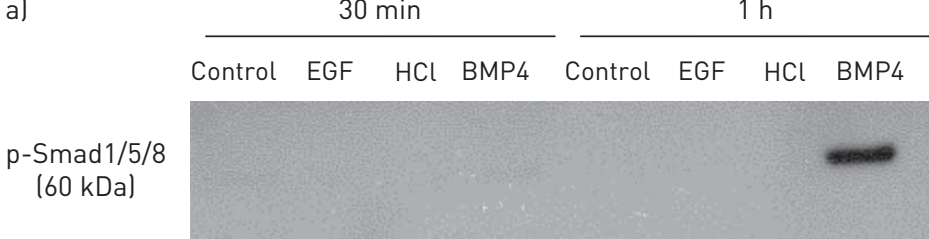

Total Smad1 $(60 \mathrm{kDa})$

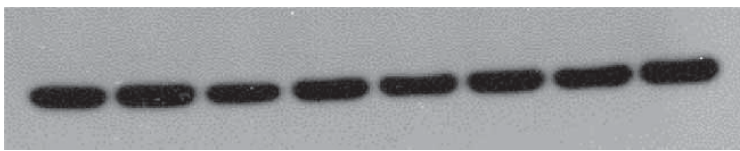

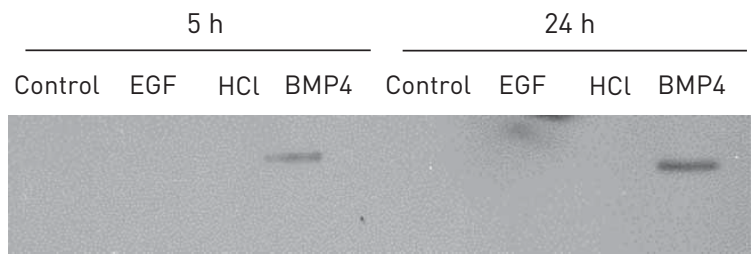

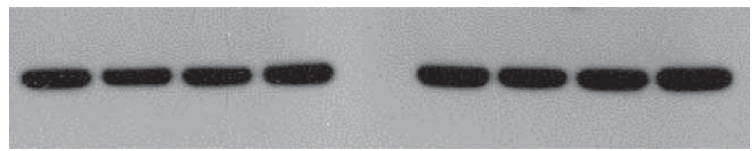

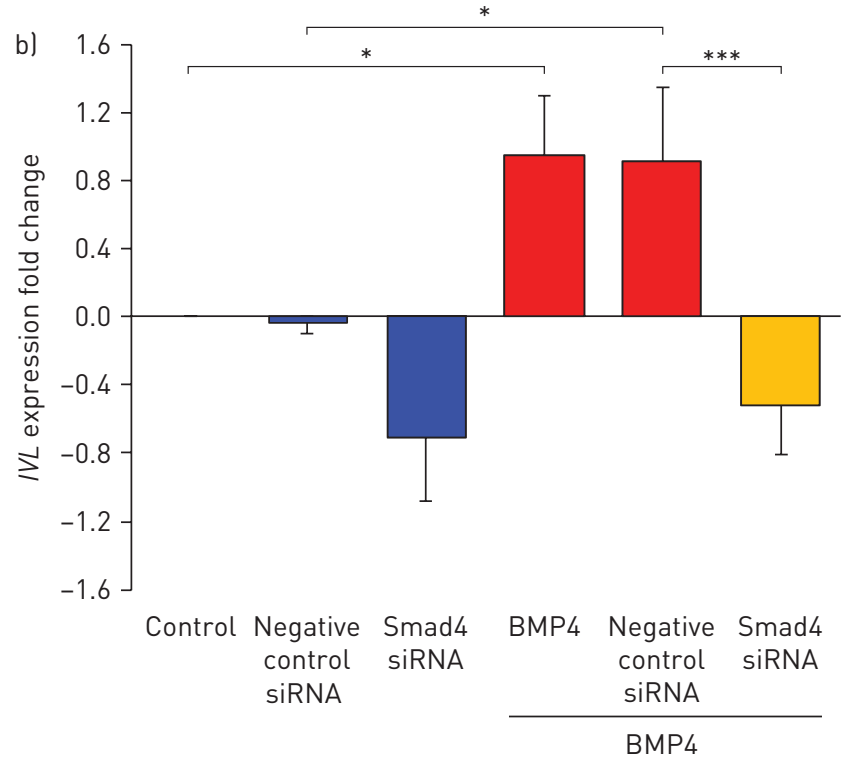

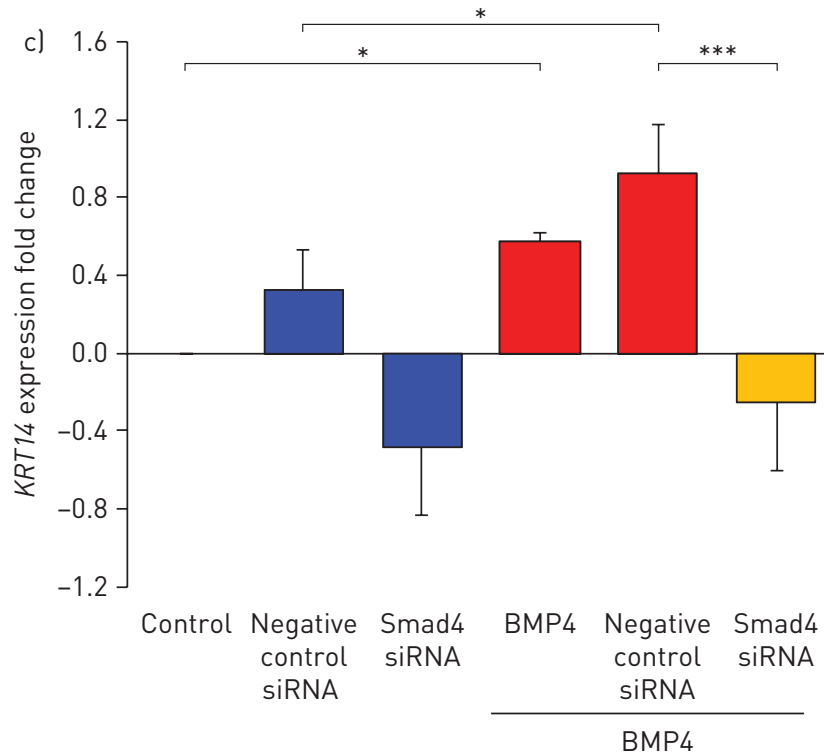

FIGURE 5 Smad signalling mediated bone morphogenetic protein 4 (BMP4)-induced squamous cell differentiation. p-Smad: phosphorylated Smad; EGF: epidermal growth factor; siRNA: small interfering RNA; BC: basal stem/progenitor cell. a) Western blot analysis shows $p-S m a d 1 / 5 / 8$ and total Smad1 protein expression of airway BCs in air-liquid interface culture (day 0) with or without BMP4 (10 ng.mL $\left.L^{-1}\right) \mathrm{stimulation}$ for $30 \mathrm{~min}, 1,5$ and $24 \mathrm{~h}$. BMP4 solvent $\mathrm{HCl}$ and EGF $\left(10 \mathrm{ng} \cdot \mathrm{mL}^{-1}\right.$; EGF does not activate BMP4 downstream Smad signalling [23]) were used as negative controls. $\mathrm{b}, \mathrm{c})$ TaqMan assessment of expression of the squamous cell markers b) IVL and c) KRT14 in BCs with BMP4 (10 ng.mL ${ }^{-1}$ ) stimulation versus untreated control for $48 \mathrm{~h}$ while silencing Smad4 by siRNA. Negative control siRNA was used as the negative control and the data were normalised to the untreated control $\left(\log _{2}\right) . n=4 .^{*}: p<0.05 ; * * *: p<0.001$.

markers (IVL and KRT14) was decreased (figure 5b and c), suggesting that Smad signalling mediated BMP4-induced human airway squamous metaplasia.

\section{Inhibition of BMP4 signalling reverses cigarette smoke extract- and EGF-induced abnormal phenotypes}

Cigarette smoke extract (CSE) is known to alter BC differentiation to suppress the generation of mucociliary epithelium and induce squamous cell differentiation (figure 6 and supplementary figure S13) [12]. To assess whether BMP4 signalling was involved in CSE-induced airway epithelial remodelling, BMP type I receptor inhibitor DMH1 was applied to BC differentiation culture in ALI culture when treated by CSE. The gene expression data showed that DMH1 significantly reversed CSE-induced upregulation of the squamous cell markers $I V L$ (figure 6a) and KRT14 (figure 6b), and downregulation of ciliated cell markers (FOXJ1 and DNAI1) (supplementary figure S13a) and secretory cell markers (SCGB1A1 and TFF3) (supplementary figure S13b).

As with CSE, we previously identified that EGF signalling plays a role in reprogramming BC differentiation to the smoking-relevant phenotypes $[5,18]$. Here, we found that inhibition of BMP4 signalling by DMH1 could restore EGF-induced abnormal phenotypes in the BC differentiation process, including downregulation of ciliated (FOXJ1 and DNAI1) and secretory cell (SCGB1A1) markers, and upregulation of squamous cell markers (IVL and KRT14) (supplementary figure S14a). However, BMP4 had no effect on the expression of amphiregulin (AREG; an EGFR ligand) (supplementary figure S14b), the upregulation of which is associated with BC and mucous cell hyperplasia [18]. 

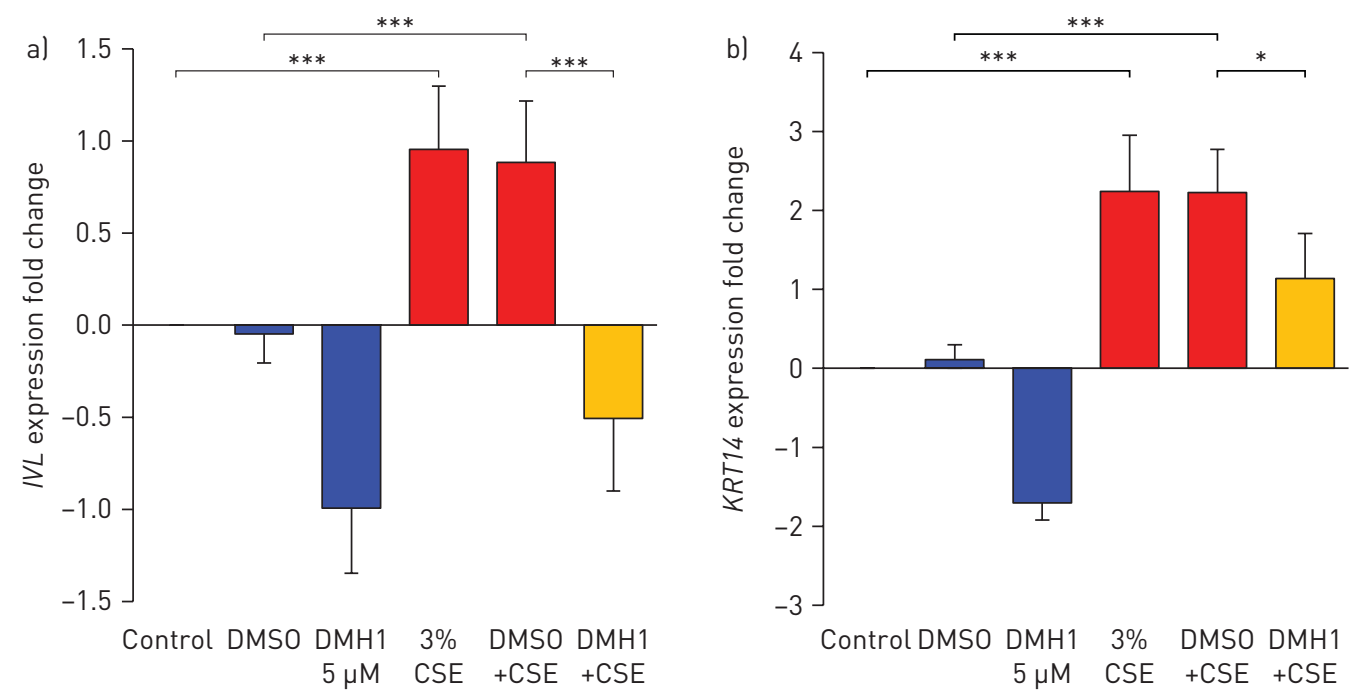

FIGURE 6 DMH1 suppressed cigarette smoke extract (CSE)-induced squamous cell differentiation. DMSO: dimethylsulfoxide; BC: basal stem/progenitor cell. a, b) TaqMan assessment of fold change $\left(\log _{2}\right.$, normalised to control) in gene expression of the squamous cell markers a) IVL and b) KRT14 in airway epithelium derived from BCs after 14 days in air-liquid interface culture. In CSE-treated groups, BCs were exposed to $3 \%$ CSE stimulation from the basolateral side versus untreated control in the absence or presence of bone morphogenetic protein 4 type I receptor inhibitor DMH1 $(5 \mu \mathrm{M})$. DMSO was used as negative control. $n=4$. ${ }^{*}: p<0.05 ;{ }^{* * *}: p<0.001$.

\section{Discussion}

COPD is a cigarette smoking-related chronic lung disease characterised by long-term reduced airflow with chronic cough, increased sputum production and shortness of breath [24]. The early pathogenesis of COPD is associated with dramatic architectural changes of airway epithelium, including BC and intermediate cell hyperplasia, decreased number of ciliated cells, shortening cilia length, mucus overproduction, goblet cell hyperplasia, and squamous metaplasia [5-13]. The present study identifies a novel mechanism that regulates airway epithelial remodelling in asymptomatic smokers and COPD smokers based on the observation that expression of BMP4 is upregulated in differentiated airway epithelium of asymptomatic smokers and COPD smokers. The upregulated BMP4 interacts with BCs, the stem/progenitor cells in the human airway, to suppress normal mucociliary differentiation and induce squamous metaplasia, i.e. processes directly relevant to the pathogenesis of COPD (supplementary figure S17).

\section{BMP4 expression in airway epithelium}

BMP4, a ligand classified with the TGF- $\beta$ superfamily, is expressed in many tissues, and plays a critical role in embryogenesis, embryonic development and homeostasis of adult organs [23]. In the developing embryonic mouse lung, BMP4 is expressed in the distal tips of the epithelium [25], and dynamics of BMP4 expression in endoderm during lung development determine lung bud morphogenesis [20] and epithelial proximal-distal patterning [21]. In the adult mouse airway, BMP4 is highly expressed in fibroblast-like cells in the mesenchyme and weakly expressed in some luminal epithelial cells in the steady state. During injury, BMP4 expression decreases in the mesenchyme and disappears in epithelial cells [26]. In addition, BMP4 has been reported to be expressed in mouse lung endothelial cells, suppressed by naphthalene injury and induced by bleomycin injury [27].

There is limited information available on BMP4 expression in human airway epithelium. Consistent with our data, BMP4 mRNA is detected in primary cultured human bronchial epithelial cells and the expression of BMP4 is increased in ALI culture [28], suggesting BMP4 may be involved in mucociliary differentiation. In the present study, taking advantage of RNA sequencing of bronchoscopy brushing epithelial cells and immunostaining of human airway epithelial biopsies from nonsmokers, asymptomatic smokers and COPD smokers, we found that BMP4 expression is very low in normal airway epithelium. In contrast, in asymptomatic smokers and COPD smokers, BMP4 expression was significantly upregulated, mostly in ciliated and intermediate cells, as well as in a subset of BCs. Unlike BMP4 expression in the mouse airway, BMP4 expression in asymptomatic healthy smokers and COPD smokers was not detected in mesenchyme and epithelial secretory cells in the human airway. Importantly, $\mathrm{BMP} 4^{+}$cells were not only observed in normal airway epithelium of smokers, but were markedly increased in abnormal airway 
epithelium in asymptomatic smokers and COPD smokers that also had abundant KRT6 expression. The expression correlation between BMP4 and KRT6, which has been related to squamous differentiation [5, $18,29]$, suggests that BMP4 is relevant to the generation of remodelled airway epithelium. In contrast to the upregulation of BMP4, the expression of other BMPs (BMP2, BMP5 and BMP6), BMP antagonists (NOG, FST, FSTL3, CHRD, CHRDL2 and TWIG2) and BMP4 receptors (BMPR2, ACVR1 and ACVR2A) did not change in airway epithelium obtained from asymptomatic smokers and COPD smokers. BMP7 and BMPR1B expression levels were increased, and BMPR1A expression levels were decreased, in asymptomatic smokers and COPD smokers, respectively, but with less dramatic change. Taken together, these data suggest that BMP4 is the main component in the BMP pathway that induces abnormal airway epithelium in asymptomatic smokers and COPD smokers. However, the mechanism of how cigarette smoking enhances BMP4 expression is unknown. It is reported that Hedgehog signalling is evoked by chronic cigarette smoke exposure in human airway epithelial cells [30] and Hedgehog signalling induces expression of BMP4 [31]. If so, the exaggerated BMP4 in smokers may be the result of activation of Hedgehog signalling in epithelial cells. BCs are stem/progenitor cells capable of differentiating into mucociliary epithelium and BCs from COPD smokers are quite different from BCs from nonsmokers [32, 33]. These observations suggest another hypothesis, i.e. that the enhanced BMP4 in differentiated airway epithelium is due to altered differentiation of BCs in COPD smokers.

\section{Exaggerated BMP4 in airway epithelium induces cigarette smoking-relevant phenotypes}

In the mouse, conditional knockout of BMP4 in the anterior foregut causes loss of the trachea [34]. During morphogenesis of the mouse lung, BMP4 in endoderm cooperates with fibroblast growth factor 10 in the distal mesenchyme to regulate branching morphogenesis [20]. BMP4 also controls endodermal proximal-distal patterning during lung development [21]. In resting adult mouse airway epithelium, BMP4 inhibits BC proliferation, while following an injury, BMP4 signalling is suppressed, allowing airway epithelial proliferation and repair [26].

In humans, BMP4 has been shown to activate the EMT response in airway epithelial cells $[22,35]$. BMP4 is also crucial for human pluripotent stem cell differentiation to lung cells [36, 37]. However, the effects of BMP4 on human BCs are still unknown. BCs are stem/progenitor cells in human airway epithelium and BCs from COPD smokers fail to generate normal airway epithelium [33], suggesting human airway BCs play a central role in the pathogenesis of smoking-related lung diseases. Based on 1) cigarette smoking reduces the junctional barrier integrity of airway epithelium, partially mediated by EGF-EGFR signalling $[5,17,18]$, to allow the particles/proteins to cross the barrier junctions of airway epithelium, and 2) our observation that BMP4 is expressed abundantly in airway epithelium of smokers, we hypothesised that upregulated BMP4 passes through the damaged barrier junctions of airway epithelium, and interacts with $\mathrm{BCs}$ to switch the normal BC self-renewal and differentiation towards smoking-relevant abnormal airway epithelium. From our data, BCs exposed to BMP4 have a decreased proliferation rate, and were not able to differentiate into normal mucociliary epithelium and were reprogrammed to generate squamous cells. Interestingly, the expression of SPDEF, a transcription factor that regulates goblet and club cell differentiation $[38,39]$, was also suppressed by BMP4. These data are in agreement with the reduction of club cells in COPD smokers [40], while opposite to the expected phenotypes of goblet cell hyperplasia in smokers [7, 10], suggesting a complicated mechanism that regulates the smoking-related phenotypes in human airway epithelium.

\section{BMP signalling pathway reprogramming of human airway epithelial differentiation}

BMP4 signals through canonical Smad-dependent and other noncanonical signalling pathways [23]. In the canonical signalling pathway, BMP4 binds to receptors, including type I and II receptors, to initiate the transduction cascade. Activation of the receptor by BMP4 phosphorylates intracellular Smad1/5/8 [23]. With the help of Smad4, the phosphorylated Smad1/5/8 translocates to the nucleus to regulate gene expression. Noncanonical pathways, like those of mitogen-activated protein kinase (MAPK), phosphoinositide 3-kinase and p38, can also be activated by BMP4 [41-43]. BMPR1A, one of the BMP type I receptors, is critical for mouse lung development [44]. Deletion of BMPR1A decreases epithelial proliferation in the distal embryonic lung, and leads to apoptosis and abnormal morphogenesis in the mouse lung [44]. We identified that BMPR1A serves as the major receptor to mediate BMP4-induced smoking-relevant abnormal phenotypes and its downstream Smad signalling mediates squamous cell differentiation as well. As BMPR1A is only expressed in a subset of BCs in vivo, we consider the BMP4-induced smoking-relevant phenotypes (decreased mucociliary epithelium and increased squamous metaplasia) would reside in a "local" area of airway epithelium. The "local changes" of airway epithelium mediated by BMP4 may represent an early pathogenesis of smoking-related diseases, including COPD.

We previously reported that CSE and EGF/amphiregulin-EGFR signalling altered the BC differentiation programme towards smoking-related lesions $[5,12,18]$, which is similar to the phenotype induced by 
BMP4. Interestingly, our data showed that blocking the BMP receptor reversed CSE/EGF-induced smokingrelated lesions, suggesting that CSE/EGF and BMP4 might share some common signalling pathways in BCs. MAPK signalling might be a candidate, as it is the downstream signalling pathway for EGF and noncanonical downstream signalling for BMP4 [45]. However, BMP4 did not change the expression of amphiregulin, suggesting that BMP4 signalling is not entirely overlapping with EGF/amphiregulin signalling.

In summary, our study identified a novel BMP4-dependent mechanism related to abnormal airway epithelial reprogramming associated with smoking and COPD. Modulation of BMP4 or the downstream receptors and signalling cascades in human airway BCs may be a potential therapeutic approach to cure or prevent the pathogenesis of smoking-induced airway disease.

Acknowledgements: We thank R. Shaykhiev and I. Chao (Dept of Genetic Medicine, Weill Cornell Medical College, New York, NY, USA) for help in experimental design and technical assistance, and N. Mohamed (Dept of Genetic Medicine, Weill Cornell Medical College) for editorial help. The biological samples in the study were obtained from a total of 100 subjects; two of these subjects were also enrolled in the bronchoscopy subset of SPIROMICS. The authors thank the SPIROMICS participants and participating physicians, investigators and staff for making this research possible. More information about the study and how to access SPIROMICS data is available at www.spiromics.org. We would like to acknowledge the following current and former investigators of the SPIROMICS sites and reading centres: Neil E. Alexis, Wayne H. Anderson, Igor Barjaktarevic, R. Graham Barr, Eugene R. Bleecker, Richard C. Boucher, Russell P. Bowler, Elizabeth E. Carretta, Stephanie A. Christenson, Alejandro P. Comellas, Christopher B. Cooper, David J. Couper, Gerard J. Criner, Ronald G. Crystal, Jeffrey L. Curtis, Claire M. Doerschuk, Mark T. Dransfield, Christine M. Freeman, MeiLan K. Han, Nadia N. Hansel, Annette T. Hastie, Eric A. Hoffman, Robert J. Kaner, Richard E. Kanner, Eric C. Kleerup, Jerry A. Krishnan, Lisa M. LaVange, Stephen C. Lazarus, Fernando J. Martinez, Deborah A. Meyers, Wendy C. Moore, John D. Newell Jr, Laura Paulin, Stephen Peters, Cheryl Pirozzi, Elizabeth C. Oelsner, Wanda K. O'Neal, Victor E. Ortega, Robert Paine III, Nirupama Putcha, Sanjeev Raman, Stephen I. Rennard, Donald P. Tashkin, J. Michael Wells, Robert A. Wise and Prescott G. Woodruff. The project officers from the Lung Division of the National Heart, Lung, and Blood Institute were Lisa Postow and Thomas Croxton.

Conflict of interest: None declared.

Support statement: These studies were supported, in part, by HL107882, HL107882-S, HL1189541, HL094284 and UL1 TR000457. SPIROMICS was supported by contracts from the NIH/NHLBI (HHSN268200900013C, HHSN268200900014C, HHSN268200900015C, HHSN268200900016C, HHSN268200900017C, HHSN268200900018C, HHSN268200900019C and HHSN268200900020C), and supplemented by contributions made through the Foundation for the NIH and the COPD Foundation from AstraZeneca/MedImmune, Bayer, Bellerophon Therapeutics, Boehringer Ingelheim Pharmaceuticals Inc., Chiesi Farmaceutici SpA, Forest Research Institute Inc., GlaxoSmithKline, Grifols Therapeutics Inc., Ikaria Inc., Nycomed $\mathrm{GmbH}$, Takeda Pharmaceutical Co., Novartis Pharmaceuticals Corp., ProterixBio, Regeneron Pharmaceuticals Inc., Sanofi and Sunovion. Funding information for this article has been deposited with the Crossref Funder Registry.

\section{References}

1 Crystal RG, Randell SH, Engelhardt JF, et al. Airway epithelial cells: current concepts and challenges. Proc Am Thorac Soc 2008; 5: 772-777.

2 Rock JR, Randell SH, Hogan BL. Airway basal stem cells: a perspective on their roles in epithelial homeostasis and remodeling. Dis Model Mech 2010; 3: 545-556.

3 Mercer RR, Russell ML, Roggli VL, et al. Cell number and distribution in human and rat airways. Am J Respir Cell Mol Biol 1994; 10: 613-624.

4 Rock JR, Gao X, Xue Y, et al. Notch-dependent differentiation of adult airway basal stem cells. Cell Stem Cell 2011; 8: 639-648.

5 Shaykhiev R, Zuo WL, Chao I, et al. EGF shifts human airway basal cell fate toward a smoking-associated airway epithelial phenotype. Proc Natl Acad Sci USA 2013; 110: 12102-12107.

6 Auerbach O, Forman JB, Gere JB, et al. Changes in the bronchial epithelium in relation to smoking and cancer of the lung; a report of progress. N Engl J Med 1957; 256: 97-104.

7 Cosio M, Ghezzo H, Hogg JC, et al. The relations between structural changes in small airways and pulmonary-function tests. N Engl J Med 1978; 298: 1277-1281.

8 Hessel J, Heldrich J, Fuller J, et al. Intraflagellar transport gene expression associated with short cilia in smoking and COPD. PLoS One 2014; 9: e85453.

9 Hogg JC, Chu F, Utokaparch S, et al. The nature of small-airway obstruction in chronic obstructive pulmonary disease. N Engl J Med 2004; 350: 2645-2653.

10 Hogg JC, Pare PD, Hackett TL. The contribution of small airway obstruction to the pathogenesis of chronic obstructive pulmonary disease. Physiol Rev 2017; 97: 529-552.

11 Leopold PL, O'Mahony MJ, Lian XJ, et al. Smoking is associated with shortened airway cilia. PLoS One 2009; 4: e8157.

12 Brekman A, Walters MS, Tilley AE, et al. FOXJ1 prevents cilia growth inhibition by cigarette smoke in human airway epithelium in vitro. Am J Respir Cell Mol Biol 2014; 51: 688-700.

13 Tilley AE, Walters MS, Shaykhiev R, et al. Cilia dysfunction in lung disease. Annu Rev Physiol 2015; 77: 379-406.

14 Crystal RG. Airway basal cells. The "smoking gun" of chronic obstructive pulmonary disease. Am J Respir Crit Care Med 2014; 190: 1355-1362.

15 Shaykhiev R, Crystal RG. Early events in the pathogenesis of chronic obstructive pulmonary disease Smoking-induced reprogramming of airway epithelial basal progenitor cells. Ann Am Thorac Soc 2014; 11: Suppl. 5, S252-S258. 
16 Ryan DM, Vincent TL, Salit J, et al. Smoking dysregulates the human airway basal cell transcriptome at COPD risk locus 19q13.2. PLoS One 2014; 9: e88051.

17 Shaykhiev R, Otaki F, Bonsu P, et al. Cigarette smoking reprograms apical junctional complex molecular architecture in the human airway epithelium in vivo. Cell Mol Life Sci 2011; 68: 877-892.

18 Zuo WL, Yang J, Gomi K, et al. EGF-amphiregulin interplay in airway stem/progenitor cells links the pathogenesis of smoking-induced lesions in the human airway epithelium. Stem Cells 2017; 35: 824-837.

19 Winnier G, Blessing M, Labosky PA, et al. Bone morphogenetic protein-4 is required for mesoderm formation and patterning in the mouse. Genes Dev 1995; 9: 2105-2116.

20 Weaver M, Dunn NR, Hogan BL. Bmp4 and Fgf10 play opposing roles during lung bud morphogenesis. Development 2000; 127: 2695-2704.

21 Weaver M, Yingling JM, Dunn NR, et al. Bmp signaling regulates proximal-distal differentiation of endoderm in mouse lung development. Development 1999; 126: 4005-4015.

22 Molloy EL, Adams A, Moore JB, et al. BMP4 induces an epithelial-mesenchymal transition-like response in adult airway epithelial cells. Growth Factors 2008; 26: 12-22.

23 Bragdon B, Moseychuk O, Saldanha S, et al. Bone morphogenetic proteins: a critical review. Cell Signal 2011; 23: 609-620.

24 Pauwels RA, Rabe KF. Burden and clinical features of chronic obstructive pulmonary disease (COPD). Lancet 2004; 364: 613-620.

25 Bellusci S, Henderson R, Winnier G, et al. Evidence from normal expression and targeted misexpression that bone morphogenetic protein (Bmp-4) plays a role in mouse embryonic lung morphogenesis. Development 1996; 122: 1693-1702.

26 Tadokoro T, Gao X, Hong CC, et al. BMP signaling and cellular dynamics during regeneration of airway epithelium from basal progenitors. Development 2016; 143: 764-773.

27 Lee $\mathrm{JH}$, Bhang $\mathrm{DH}$, Beede $\mathrm{A}$, et al. Lung stem cell differentiation in mice directed by endothelial cells via a BMP4-NFATc1-thrombospondin-1 axis. Cell 2014; 156: 440-455.

28 Ross AJ, Dailey LA, Brighton LE, et al. Transcriptional profiling of mucociliary differentiation in human airway epithelial cells. Am J Respir Cell Mol Biol 2007; 37: 169-185.

29 Araya J, Cambier S, Markovics JA, et al. Squamous metaplasia amplifies pathologic epithelial-mesenchymal interactions in COPD patients. J Clin Invest 2007; 117: 3551-3562.

30 Lemjabbar-Alaoui H, Dasari V, Sidhu SS, et al. Wnt and Hedgehog are critical mediators of cigarette smoke-induced lung cancer. PLoS One 2006; 1: e93.

31 Wang DH, Tiwari A, Kim ME, et al. Hedgehog signaling regulates FOXA2 in esophageal embryogenesis and Barrett's metaplasia. J Clin Invest 2014; 124: 3767-3780.

32 Ghosh M, Miller YE, Nakachi I, et al. Exhaustion of airway basal progenitor cells in early and established chronic obstructive pulmonary disease. Am J Respir Crit Care Med 2018; 197: 885-896.

33 Staudt MR, Buro-Auriemma LJ, Walters MS, et al. Airway basal stem/progenitor cells have diminished capacity to regenerate airway epithelium in chronic obstructive pulmonary disease. Am J Respir Crit Care Med 2014; 190: 955-958.

34 Li Y, Gordon J, Manley NR, et al. Bmp4 is required for tracheal formation: a novel mouse model for tracheal agenesis. Dev Biol 2008; 322: 145-155.

35 McCormack N, O'Dea S. Regulation of epithelial to mesenchymal transition by bone morphogenetic proteins. Cell Signal 2013; 25: 2856-2862.

36 Huang SX, Islam MN, O'Neill J, et al. Efficient generation of lung and airway epithelial cells from human pluripotent stem cells. Nat Biotechnol 2014; 32: 84-91.

37 Wong AP, Bear CE, Chin S, et al. Directed differentiation of human pluripotent stem cells into mature airway epithelia expressing functional CFTR protein. Nat Biotechnol 2012; 30: 876-882.

38 Chen G, Korfhagen TR, Xu Y, et al. SPDEF is required for mouse pulmonary goblet cell differentiation and regulates a network of genes associated with mucus production. J Clin Invest 2009; 119: 2914-2924.

39 Rajavelu P, Chen G, Xu Y, et al. Airway epithelial SPDEF integrates goblet cell differentiation and pulmonary Th2 inflammation. J Clin Invest 2015; 125: 2021-2031.

40 Lumsden AB, McLean A, Lamb D. Goblet and Clara cells of human distal airways: evidence for smoking induced changes in their numbers. Thorax 1984; 39: 844-849.

41 Derynck R, Zhang YE. Smad-dependent and Smad-independent pathways in TGF-beta family signalling. Nature 2003; 425: 577-584.

42 Lee MY, Lim HW, Lee SH, et al. Smad, PI3K/Akt, and Wnt-dependent signaling pathways are involved in BMP-4-induced ESC self-renewal. Stem Cells 2009; 27: 1858-1868.

43 Yamaguchi $\mathrm{K}$, Shirakabe K, Shibuya $\mathrm{H}$, et al. Identification of a member of the MAPKKK family as a potential mediator of TGF-beta signal transduction. Science 1995; 270: 2008-2011.

44 Eblaghie MC, Reedy M, Oliver $\mathrm{T}$, et al. Evidence that autocrine signaling through Bmprla regulates the proliferation, survival and morphogenetic behavior of distal lung epithelial cells. Dev Biol 2006; 291: 67-82.

45 Zhou Q, Heinke J, Vargas A, et al. ERK signaling is a central regulator for BMP-4 dependent capillary sprouting. Cardiovasc Res 2007; 76: 390-399. 